\title{
Presentation of the Howland Award to Louis K. Diamond
}

\author{
Cuarles A. Janeway ${ }^{[10]}$ \\ Harvard Medical School and Children's Hospital Medical Center, Boston, Massachusetts, USA
}

It is a pleasure to present American pediatrics' most cherished award to a friend, who has served as my kindly mentor in pediatrics throughout our 26 years of association at the Children's Hospital. The American Pediatric Society has chosen Louis K. Diamond for this year's John Howland Award because he is and has been a great pediatrician, an extraordinarily effective teacher, a remarkably productive clinical investigator, and, for part of his career, an important public servant.

His academic career (Table $\mathrm{I}$ ) began in a New York

Table 1 . Academic career

\begin{tabular}{ll}
\hline 1919 & Townsend Harris Hall, New York \\
1923 & A.B. Harvard College \\
1927 & M.D. Harvard Medical School \\
1927 & Rockefeller Institute (Florence Sabin) \\
$1927-1933$ & Training and Research in Pediatrics and Pathology \\
$1933-1968$ & Pediatric Staff, Children's Hospital \\
& Chief, Hematology Division \\
Associate Physician-in-Chief \\
$1933-1968$ Pediatric Faculty, Harvard Medical School \\
$1949-1968 \quad$ Associate Professor, Professor \\
$1968 \quad$ Professor of Pediatrics, Emeritus \\
$1968-\quad$ Professor of Pediatrics, University of California \\
\hline
\end{tabular}

high school for talented students, thence to Harvard College, where pediatrics almost lost him to chemistry before he entered the Harvard Medical School.

After graduation in 1927, already pointing toward hematology, he spent some time working with Florence Sabin at the Rockefeller Institute, but then returned for clinical training in pediatrics and pathology to Boston where he remained for 41 years, rising to the rank of Professor of Pediatrics at the Harvard Medical School and Chief of Hematology and Associate Physician-in-Chief at the Children's Hospital Medical Center. In 1968, having become Professor Emeritus at Harvard, he turned his back on the Atlantic Coast and began a second career as Professor of Pediatrics at the University of California in this wonderful city facing the Pacific.

Dr. Diamond is no ivory tower professor. His life includes a substantial portion of public service, including 3 hectic years as the first Technical Director of the National Blood Program of the American Red Cross, as well as service to the National Research Council and the National Institutes of Health (Table II).

Table II. Public service

(First) Technical Director, National Blood Program, American Red Cross

Subcommittee on Blood, National Research Council

Hematology Study Section, Human Embryology and Development Study Section, National Institutes of Health

Founder and Director, Blood Grouping Lab; Vice President, Center for Blood Research

Table III. Honors

1946 Mead Johnson Award, American Academy of Pediatrics 1951. Carlos J. Finlay Gold Medal, Cuba

1959 Award of Merit, the Netherlands Red Cross

1963 Karl Landsteiner Award, American Association of Blood Banks

1964 Theodore Roosevelt Medal for Distinguished Public Service in Science

1966 Award for Scientific Research in Mental Retardation, Joseph P. Kennedy, Jr., International Foundation

His multifaceted activities have deservedly brought him numerous awards (Table III). His contributions to the management of erythroblastosis fetalis won him the Mead Johnson Award of the American Academy of Pediatrics in 1946. Then followed several awards 
for his contributions to blood banking and safe transfusion. Next, his work on the prevention of kernicterus in erythroblastosis led to the 1966 Award for Scientific Research in Mental Retardation of the Joseph P. Kennedy, Jr., International Foundation. Today we celebrate his contributions to pediatrics with the Howland Award.

Let us examine some highlights of Dr. Diamond's distinguished career. As an eager young man he prepared to enter medical school in 1923. Six years later, in 1929, he stands as a confident pediatric resident at the Children's Hospital, with his great teacher, Kenneth Blackfan (Fig. 1). After Blackfan's untimely death from lung cancer, Dr. Richard M. Smith, an eminent practitioner, served as Head of the Department of Pediatrics through the period of the second World War on condition that three younger men-Diamond, Clement Smith, and John Davies-would carry the bulk of the clinical and teaching load.

Up to this time, Dr. Diamond, like most of the younger clinical teachers of that period, had had to supplement his meager academic salary by pediatric practice: an experience which gave his clinical teaching a strong foundation in reality, and deepened his understanding of patients and their parents. The opportunity to devote himself full time to academic pediatrics came in 1942, when, in order to apply the new knowledge of the Rh system to blood transfusion and the management of erythroblastosis, Dr. Diamond organized the Blood Grouping Laboratory, which became a world-renowned center for research on this disease and a regional center for its treatment. With this laboratory as a base for work on erythroblastosis, and with what then seemed like an enormous grant of 10,000

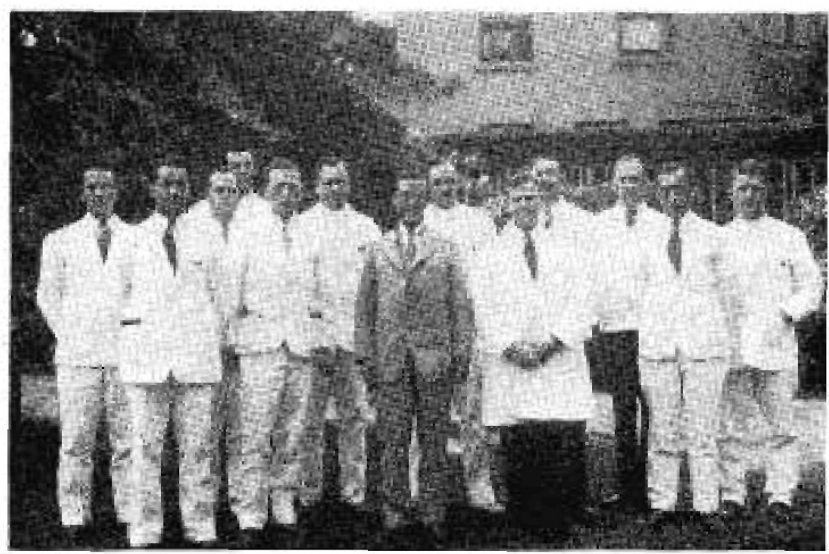

Fig. 1. The house staff at the Children's Hospital for 1929-1930. Dr. Blackfan stands in the center in a business suit; Dr. Diamond is at the end of the front row on the left. dollars a year for 5 years for research in hematology from the Charles H. Hood Foundation, Dr. Diamond was ready to create the field of pediatric hematology.

Because of his expertise in this field, Dr. Diamond was soon enlisted as a collaborator by Professor Edwin Cohn, who was developing the methods of plasma fractionation during the early Forties. Dr. Diamond was the first pediatrician to use a purified human plasma fraction in the management of hemophilia in children. This chart, prepared by Dr. Diamond, shows the effect of fraction $I$ on the coagulation time of a boy with hemophilia, who was carried successfully through a dental extraction without excessive bleeding (Fig. 2). This study depicting both the observable clinical effect and laboratory proof of the action of antihemophilic globulin, is typical of Dr. Diamond's clinical research. He had the complete confidence of his patients; he needed no Committee on Human Investigation to monitor his instinctive ethical standards, and he could plan and carry out a decisive clinical trial.

It was his involvement in the work of Dr. Cohn's group, and his expertise in the field of blood transfusion, that led to his selection as the first Technical Director for the newly created National Blood Program of the American Red Cross in 1948. This was an arduous, and sometimes tedious pioneering task, but in 3 years, he was able to establish high technical standards for a program which has become one of the major health resources of this country.

Upon his return from this taxing administrative job, he devoted himself full time to pediatric teaching and research, to sharing my responsibilities for patient care as Associate Physician-in-Chief of the hospital, and for the department as its head during my two sabbatical leaves. He also began the serious business of training pediatric hematologists. The record of his pediatric hematology training program is an extraordinary one. Had all other training programs been like it, we would probably not be involved in our present difficulties over training grants. His 60 or more former trainees are located in 16 states and 13 foreign countries. Many of them are full professors; almost everyone of them is in an academic position. It was a rigorous program, involving a healthy mix of clinical responsibility for patients with research activities in the various laboratories he had established. However, it wasn't all work and no play. This group of trainees, with their master, don't look too downtrodden (Fig. 3). It includes Doris Howell to his right, now Chairman of the Department of Pediatrics at the Medical College of Pennsylvania, and on his left, Jack Hartmann, Pro- 


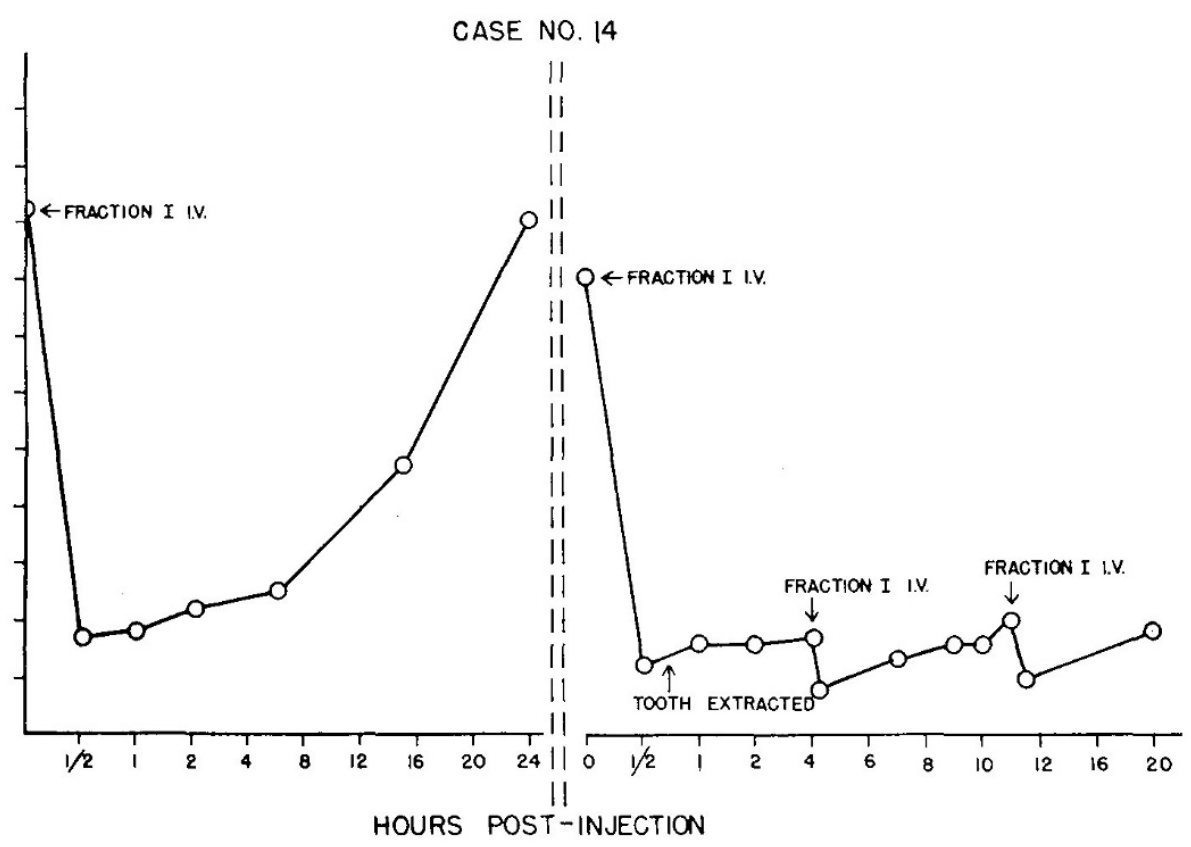

Fig. 2. The response of the coagulation time of a boy with hemophilia to Cohn fraction I. After demonstrating its efficacy, Dr. Diamond permitted an essential dental extraction, and by maintaining a normal coagulation time over several days was able to prevent the postextraction oozing and bleeding which had been the rule before.

fessor of Pediatrics and Hematologist-Oncologist at the Children's Orthopedic Hospital in Seattle.

What has made Lou Diamond so effective? First, he is an exceptionally, dedicated physician, able to concentrate every faculty, as well as his vast store of knowledge and clinical experience upon helping his patient. Second, he is an investigator who has always been quick to see the clinical possibilities arising out of scientific advances. Third, he has had the drive to turn his vision of such potentialities into reality. For example, in 1932, with Baty and Blackfan, he presented

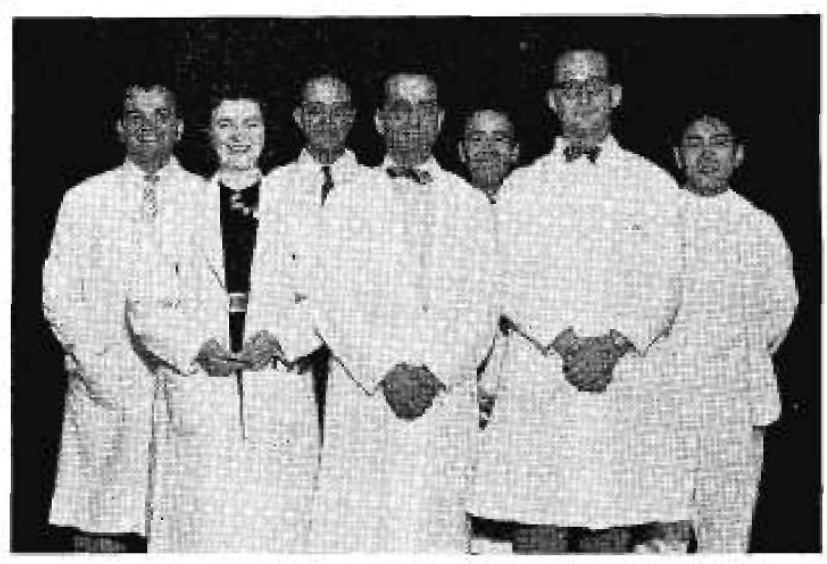

Fig. 3. Fellows in hematology with Dr. Diamond (center) for the year 1954-1955. evidence, from a detailed pathologic and clinical analysis of 20 cases and an extensive review of the literature, that what had previously been considered four different diseases-fetal death with erythroblastosis in the tissues, fetal hydrops, congenital anemia of the newborn, and icterus gravis neonatorum-were differing clinical manifestations of a single pathologic process, called erythroblastosis fetalis [6]. Nine years later, Philip Levine showed that this process was due to isoimmunization of an Rh-negative mother by the red cells of an Rh-positive fetus. Following this discovery, Dr. Diamond enlisted the collaboration of a group of Boston hospitals in founding the Blood Grouping Laboratory, to provide the necessary laboratory support for clinical application of this new knowledge. He worked out a method with Neva Abelson and Ronald Denton for titration of the $\operatorname{IgG}$ antibody which produced the disease, as distinct from the IgM antibody which did not cross the placenta $[3,7]$. With F. H. Allen [5] he developed a simple, practical technique for exchange transfusion which had already been suggested for treatment by others. During the next two decades, he and his collaborators-Fred Allen, Victor Vaughan, Sydney Gellis, and David Hsia-systematized the indications for exchange transfusion, not just to save life, but to prevent brain damage from kernicterus [1, 4]. For this he received, with Wiener and Levine, the Award for 


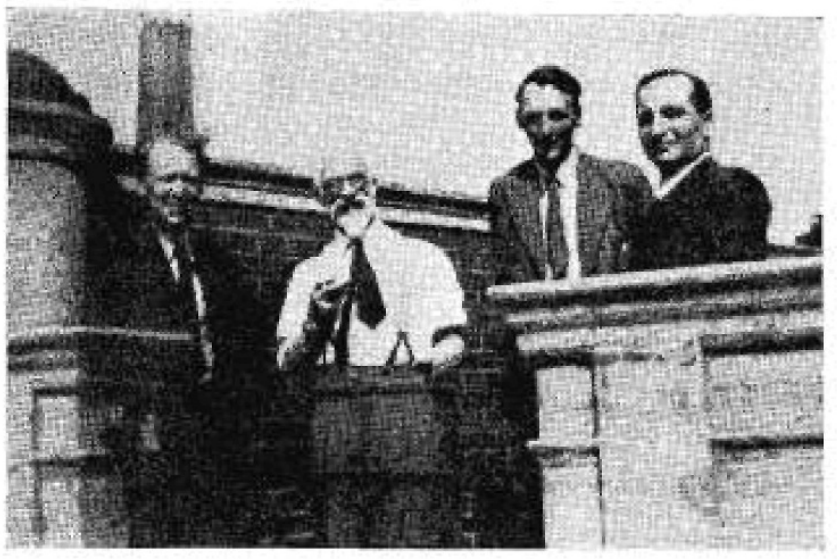

Fig. 4. Dr. Diamond on a visit to Sir Ronald Fisher at Cambridge University, England. From left to right: Race, Fisher, Mollison, and Diamond.

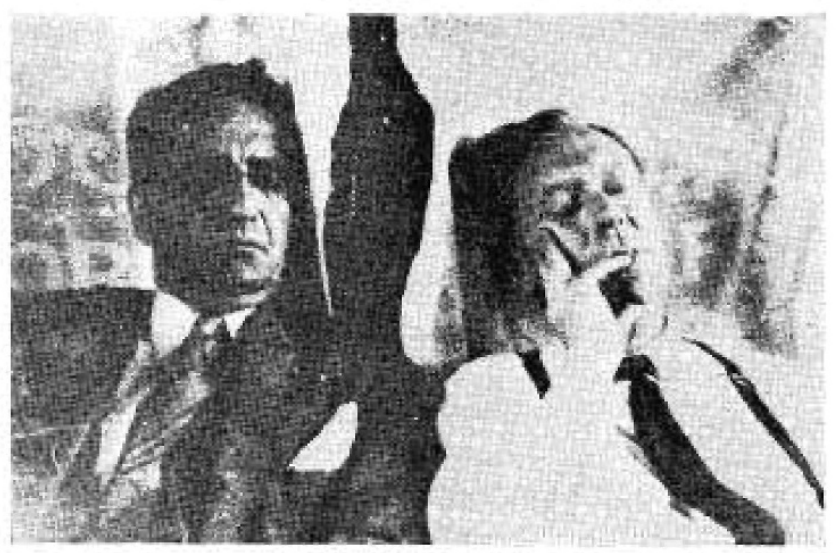

Fig. 5. Drs. Diamond and Race on the train back to London after a long day in Cambridge.

Scientific Research in Mental Retardation of the Joseph P. Kennedy, Jr., International Foundation. As he wrote in Pediatrics for January 1968, "Rarely has it been our good fortune to have a disease recognized, its cause clearly determined, its treatment successfully developed to a great extent and then its prevention found, all in one generation" [2]. Lou Diamond played a major role in this great achievement, and for that alone deserves a place in the pediatric hall of fame, but there are many other reasons for his selection for the John Howland Award.

Dr. Diamond's experience in the Blood Grouping Laboratory made him an international figure. Here is a picture taken in Cambridge, England, of what might be called the "four horsemen of the blood groups,"
Fisher and Race, the basic scientists on the right, and on the left, Diamond and Mollison, who applied their work to patients on both sides of the Atlantic (Fig. 4). These international visits had their lighter moments, such as a tour of the pubs with Race, the inevitable results showing on the return trip to London by train (Fig. 5).

The blood groups led Dr. Diamond far into human genetics. He foresaw its tremendous importance for pediatrics, encouraged Park Gerald to enter the field, sent him to London to study, and established laboratories for him at the Children's Hospital. Dr. Diamond also recognized the importance of biochemistry for elucidating the pathogenesis of the various hemolytic syndromes of childhood. For this, he was able to lure his successor, David Nathan, from Frank Gardner's laboratory in the department of medicine into pediatrics and thus to assure a bright future for the hematology division he had created. There are many other facets of his research-on the spleen or on aplastic anemia, and his encouragement of Chester Alper in automating immunochemical measurement of the plasma proteins-which we must omit for lack of time.

In closing this introduction of the 1973 Howland awardee, who was president of this society in 1966, we must pay our respects to someone whose loyalty and support have made his accomplishments possible. Flo Diamond not only brought music into Lou's life, but contributed a remarkable set of genes, as shown by the careers of their talented, able children.

And now, Dr. Diamond, the podium is yours as the recipient of the John Howland Award for 1973.

References and Notes

1. Allen, F. H., JR., And Diamond, L. K.: Erythroblastosis Fetalis, Including Exchange Transfusion Technique (Little Brown and Co., Boston 1958).

2. Diamond, L. K.: Protection against $\mathrm{Rh}$ sensitization and prevention of erythroblastosis fetalis. Pediatrics, 41 : 1 (1968).

3. Diamond, L. K., and Abelson, N. M.: Detection of Rh sensitization: evaluation of tests for $\mathrm{Rh}$ antibodies. J. Lab. Clin. Med., 30: 668 (1945).

4. Hsia, D. Y. Y., Allen, F. H. JR., Gellis, S. S., and Diamond, L. K.: Erythroblastosis fetalis VIrr. Studies of serum bilirubin in relation to kernicterus. New Engl. J. Med., 247: 668 (1952).

5. Diamond, L. K., Allen, F. H., Jr., and Thomas, W. O., Jr.: Erythroblastosis fetalis VII. Treatment with exchange transfusion. New Engl. J. Med., 244: 39 (1951).

6. Dramond, L. K., Blackfan, K. D., and Baty, J. M.: Erythroblastosis fetalis and its association with universal edema of the fetus, icterus gravis neonatorum and anemia of the newborn. J. Pediat. 1: 269 (1932). 
7. Diamond, L. K., ANd Denton, R. L.: Rh agglutination in various media with particular reference to the value of albumin. J. Lab. Clin. Med., 30: 821 (1945).

8. This address was presented at the Annual Meeting of the American Pediatric Society, San Francisco, May 18, 1973.

9. Dr. Charles A. Janeway is Thomas Morgan Rotch Profes- sor of Pediatrics, Harvard School, and Physician-in-Chief, Children's Hospital Medical Center, Boston, Mass.

10. Requests for reprints should be addressed to: Charles A. Janeway, M.D., Children's Hospital Medical Center, 300 Longwood Ave., Boston, Mass. 02115 (USA).

11. Received for publication June 7, 1973. 